\title{
A qualitative analysis of innovation adoption in the olive oil extraction process
}

Article

Published Version

Zoccali, D. and Gadanakis, Y. (2019) A qualitative analysis of innovation adoption in the olive oil extraction process. International Journal of Food and Beverage Manufacturing and Business Models, 4 (1). pp. 38-56. ISSN 2379-7509 doi: https://doi.org/10.4018/IJFBMBM.2019010103 Available at https://centaur.reading.ac.uk/81323/

It is advisable to refer to the publisher's version if you intend to cite from the work. See Guidance on citing.

To link to this article DOI: http://dx.doi.org/10.4018/IJFBMBM.2019010103

Publisher: IGI Global

All outputs in CentAUR are protected by Intellectual Property Rights law, including copyright law. Copyright and IPR is retained by the creators or other copyright holders. Terms and conditions for use of this material are defined in the End User Agreement.

\section{www.reading.ac.uk/centaur}

\section{CentAUR}

Central Archive at the University of Reading 
Reading's research outputs online 


\section{A Qualitative Analysis of Innovation Adoption in the Olive Oil Extraction Process}

Domenico Zoccali, School of Agriculture, Policy and Development, University of Reading, Reading, UK Yiorgos Gadanakis, School of Agriculture, Policy and Development, University of Reading, Reading, UK

(iD) https://orcid.org/0000-0001-7441-970X

\section{ABSTRACT}

Pressures on the Italian olive oil sector have increased over the past few years due to seasons of bad weather, small innovation capacity and limited long-term investment plans. Thus, it is of interest to explore signs of positive attitude towards innovation investment in the agricultural sector. The focus has been on technologies employed in the extraction process, since yield and quality of olive oil are mostly affected by this stage. To define the determinants of innovation adoption, 13 managers were interviewed. Questions covered organisation factors, personal factors, social factors, the impact of the olive oil value chain and the cost of the extraction machinery. The results of the thematic analysis showed that determinants of innovation adoption were: perceived usefulness, personal innovativeness, prior experience, influence of peers, training and managerial support, and the relative importance of quality, while major challenges are the lack of financial funds, demand pressure from customers, and lack of early warning systems to tackle bad weather conditions.

\section{KEYWORDS}

Determinants, Innovation Adoption, Italy, Lazio Region, Olive Oil Extraction 


\section{INTRODUCTION}

Olive growing represents a major feature of the socio-cultural heritage of the Mediterranean basin (European Commission, 2012), where olive oil extraction has been a major source of income and employment for centuries (Orlandi et al., 2017). This area accounts for more than $90 \%$ of the global production, which is equivalent to nearly 2.33 million tonnes of olive oil (Niavis et al, 2018) and represents the region where the main producers are located (FAOSTAT, 2015). Spain is currently the biggest producer in the world with 1,090.5 million tonnes of extracted olive oil, while Italy and Greece are respectively the second and third most important producers with approximately 320,000 and 300,000 tonnes of olive oil (International Olive Oil Council, 2018). In addition to being one of the largest producers worldwide, exporting approximately $40 \%$ of its production, Italy is the biggest importer of extra-virgin olive, accounting for $78 \%$ of European imports (Sabbatini, Gadanakis, and Areal, 2016), as it is also the biggest consumer in the world (International Olive Oil Council, 2015). Moreover, Italy has the greatest diversity of olives and the highest land productivity in the world, making its production large and unique (European Commission, 2012). However, despite the satisfactory 2017/2018 crop season, agricultural production performance in Italy has been very volatile in the last five years, with poor harvests following abundant ones (International Olive Oil Council, 2018). Indeed, it has been common to experience harsh weather, either too hot or cold for Italian standards, or episodes of olive fruit fly attacks, negatively affecting the total production (USDA, 2017). Furthermore, prices have also been influenced by the closure of olive farms, which caused an inflationary pressure in the olive oil sector (Zecca and Rastorgueva, 2014). Another crucial aspect emerged from a recent analysis of the most important Italian agri-food exports, which showed that competition in international markets for Italian olive oil is growing, and it is increasingly relying on its high quality and sensory characteristics (Carbone et al, 2015). Moreover, levels of consumption and production globally are soaring, particularly in new markets outside Europe, such as Argentina and California, which possess favourable climatic condition for the cultivation of olives (Monteleone and Langstaff, 2013). Thus, in order to meet these challenges and maintain their competitive advantage, Italian olive oil producers are compelled to adopt innovation practices that cut down inefficiencies and increase quality, through timesaving and yield-boosting systems. In particular, emphasis is given to the extraction process, as this is the stage of production which has the highest impact on quality and yield of olive oil (Chiavaro, 2014). Hence, the main objective is to understand the determinants of innovation adoption in the olive oil extraction process. Specifically, the main aim is to analyse factors developing innovation capacity within refineries, while considering potential barriers to the uptake. However, innovation is a process that occurs at various levels in an organisation. Thus, it is appropriate to provide a definition that serves the aims and objectives of the current study. Hence, according to Baregheh, Rowley, and Sambrook (p. 1334, 2009) innovation can be defined as the: "the multi-stage process whereby organizations transform ideas into new/improved 
products, services or processes, in order to advance, compete and differentiate themselves successfully in their marketplace." Particular emphasis is therefore given to technologies employed at the refinery level, while other innovative services and processes within companies are assumed to be embedded in the management capacity of the organisation.

\subsection{Structure of the Paper}

The remaining of the paper is organised into the "Materials and Methods" section, where: the theoretical framework of the research is presented, following a brief review of the available approaches and the rationale of the appropriateness of the chosen one; the usefulness of qualitative research and its link with the theoretical framework are discussed; qualitative interviews for collecting the data are introduced; the area of research, the sample of the study and recruitment process are analysed; and ultimately thematic analysis was highlighted. The main findings of thematic analysis are discussed in the "Results" paragraph, through employing direct quotes and focusing on each determinant of innovation adoption separately. Then, the results are compared to the existing literature, in order to appreciate if they are in line or in contrast with it, and the main barriers to the uptake are addressed and sensible ways to tackle them are proposed. Finally, the "Limitations of the research and concluding remarks" section illustrates the main drawbacks of this research and provides recommendations for further studies.

\section{MATERIALS AND METHODS}

\subsection{Theoretical Framework}

\subsubsection{The Theory of Reasoned Action}

The Theory of Reasoned Action (TRA) was introduced by Fishbein (1967) and later formalised by Fishbein and Ajzen (1975). This model theorised that a person's intention to behave in a certain way depends essentially on two factors: the "attitude" towards the particular behaviour, and the individual's perception of the social pressure to adopt that behaviour, which is embodied by the "subjective norms". Attitudes are linked to the beliefs about the outcomes of the behaviour and their evaluation, while the subjective norms regard how others expect an individual to behave and the motivation to comply with such referents (Ajzen, 2005). Ultimately, the relative importance of attitudinal and normative components determines the intention to adopt the behaviour (Ajzen and Fishbein, 1980). In the case of this model, the uptake of technology is perceived as a human behavioural issue and the TRA is used to identify barriers and drivers to its adoption (Park and Dorward, 2007).

\subsubsection{The Technology Acceptance Model}

Davis (1989) proposed the Technology Acceptance Model (TAM), in order to explain an individual's behavioural intention to use a technological innovation. This theory includes two primary predictors, which influence the dependent variable: perceived 
ease of use and perceived usefulness (Davis, 1989). Over the years, the TAM has experienced a series of modifications, which included new variables. Namely: external precursors, such as situational involvement (Jackson et al., 1997) and prior experience with innovation (Oh et al., 2003); contextual factors, such as gender, culture (Huang et al., 2003), and technology characteristics (Plouffe et al., 2001), that are intended as moderators; and consequence measures, such as perceptual and actual usage (Szajna, 1996; Davis and Venkatesh, 2004).

\subsubsection{Model of Innovation Adoption by Frambach and Schillewaert}

Frambach and Schillewaert (2002) carried out a study on the set of factors that influence acceptance of new products by organisations. Their main contribution to the literature was that the characteristics of the adopter, in terms of size of the organisation and its strategic posture and innovativeness, enhanced receptiveness towards new solutions and adoption rate. Moreover, supplier marketing efforts can stimulate adoption, thanks to an effective targeting of the innovation and communication of risk reduction and benefits. On the other hand, perceived innovation characteristics are also important. Specifically, an organisation would be attracted by a new product if this one is compatible with its structure, it has a reasonable level of complexity, and it yields a relative economic advantage.

\subsubsection{Enhanced Model of Innovation Adoption}

This study is based on the theoretical framework of innovation adoption developed by Talukder (2011). The framework builds on the three conceptual models of reasoned action (TRA), the technology acceptance model (TAM), and the theoretical model of innovation adoption formulated by Frambach and Schillewaert (2002). Talukder's model serves the objectives of this study since it connects successfully previous theories of innovation adoption and improves them by adding new determinants, while testing their statistical significance. Specifically, there are four sets of variables this model employs: individual factors, social influence, organisational factors, and demographics (Talukder, 2011).

"Individual factors" reflect: "an individual's cognitive interpretation of innovation and himself”' (Lewis et al., 2003, p. 663) and analyse five elements. Perceived usefulness was introduced by the TAM and is the degree to which a person believes an innovation improves his/her organisation's performance (Bhattacherjee \& Harris, 2009). Personal innovativeness, which is the tendency of a person to accept an innovation within a product class, independent of the communicated experience of others (Frambach and Schillewaert, 2002). A further element is prior experience with any innovations (Talukder, 2011). Lastly, we have image, which is intended as the degree to which innovation increases one's image within the organisation, and enjoyment with innovation, which refers the level of satisfaction an individual obtains from using an innovation (Talukder, 2011). "Social influence", the second variable of this theoretical framework, is instead embodied by two factors. Peers represent the extent to which workers are influenced by colleagues to adopt an innovation, while social network 
relates to the influence members of an organisation exert on other workers employed in different roles by other companies (Talukder, 2011). Furthermore, "organizational factors" represent the third variable of the model and, according to Frambach and Schillewaert, (2002), affect people's awareness of practical aspects of innovation, such as functionality. Training is needed to enhance workers' knowledge and skills in using innovations, while managerial support regards the allocation of resources and encouragement to adopt them (Talukder, 2011). Incentives, instead, are social persuasions, linked to rewards an organisation gives to innovators (Talukder, 2011). "Demographics" are the last factor considered by the model and include gender, age, academic division, qualifications, occupation category, and tenure (Talukder, 2011). Although the TRA and TAM did not consider them specifically, they acknowledged that these factors are critical in influencing behaviour. In particular, age, gender, and academic division were tested to have a considerable impact on adoption (Igbaria, 1993; Lee et al., 2005). Ultimately, all these factors trigger a behavioural intention, which, if it is positively held, leads to the adoption of innovations (Talukder, 2011). However, the theoretical framework of this research will also consider the impact of the machinery cost and the processes in the extraction of olive oil, as these are parameters that can influence the decision of adoption of innovation technologies. That is because they affect the way raw materials are processed (Caiazza et al., 2016). Also, investments in traditional extraction presses or in the modern continuous system influence margins and can potentially delay future expenditures (Salomone et al., 2015).

\subsection{The Link Between Qualitative Research and the Theoretical Framework}

Qualitative research is a powerful method to familiarise with and gain in-depth knowledge of social and economic realities, because it is descriptive in nature and provides comprehensive information in line with a study's requirements and objectives (Kent, 2007; Brahma, 2009). Moreover, carrying out a qualitative research assesses non-quantifiable determinants of a study involving individuals and organisations and allows to understand decision-making processes and attitudes of individuals (Bryman and Bell, 2015; Atieno, 2009). That is especially useful to this research's theoretical framework, which is mainly focused on individual and social determinants of innovation adoption in olive oil refineries. Furthermore, in order to provide the best supporting evidence to describe the variables introduced by the theoretical framework, primary data collected through qualitative tools can help provide a reliable picture of the situation, in a way that reflects reality (Sullivan, 2001).

\subsection{Data Collection}

The study employs interviews, as their aim is to draw out experiences, perceptions and feelings of participants through a dialogue, which is directed towards specific topics by the interviewer (Edwards and Holland, 2013). Specifically, this research uses semistructured interviews, as they observe a common format which allows for comparison and at the same time consent participants to respond in their own terms, while the 
interviewer is able to adjust the questions to each respondent's answers (Edwards and Holland, 2013). In particular, interviews were arranged with key informants that had an important role in the organisation and were willing to cooperate and communicate their knowledge in an intelligible way (Marshall, 1996). They were chosen only depending on their availability and willingness to participate in the study, without following any inclusion/exclusion criteria. Furthermore, to ensure this research minimises the risk of harm to interviewees, it successfully applied for ethical clearance for data collection from the University of Reading Research Ethics Committee.

\subsection{Structure of the Interviews}

The list of questions used as a guideline in the interviewing process considered the following determinants. Organisation factors referred to the size of the company, the number of employees, the role of qualified and unqualified workers, the presence or absence of training schemes, medium to long term expansion goals and investment plans, potential application for financial aid, and time of the upgrades of the machinery. Personal factors, instead, focused on the age of the respondent, his/her knowledge of the olive oil sector, personal opinions on the technology his/her company had in place, and attitudes towards innovation and traditional methods. Furthermore, there were questions designed to study the social influence of local refineries on the technologies adopted in the company. They specifically concerned networking opportunities and peer pressure. Lastly, a set of questions covered the impact of the olive oil value chain, with regards to the technologies used to improve the standard quality properties required by the industry and the influence on future investment decisions.

\subsection{The Region Under Investigation}

The area of focus is the Lazio region, located in central Italy, as this region shows a high degree of concentration of firms (between $91.2 \%$ and $91.8 \%$ ) applying for financial measures to support competitiveness in the agricultural sector (De Rosa and McElwee, 2015). This positively influences the entrance of young entrepreneurs, and consequently demonstrates a good attitude towards rural planning and development (De Rosa and McElwee, 2015). Moreover, the Lazio region is the $5^{\text {th }}$ biggest producer in the country and extracted 83,910 tonnes of olive oil in 2014 (ISTAT, 2015). In particular, olive growing is the most important agricultural activity in the region, as 67,996 agricultural holdings are involved in this sector and cover an area of 67,438 hectares, which represent around $70 \%$ of the total utilised agricultural area (Palazzo and Aristone, 2017). Namely, around $90 \%$ of these agricultural holdings are familyrun mills and their average size is small, as they extract between 1,000-5,000 tonnes of olive oil, while medium-sized mills produce between 5,000-10,000 and 10,00015,000 tonnes of olive oil, and large mills work with more than 15,000 tonnes of olive oil (ISMEA, 2015). 


\subsection{Sample of the Study}

Participants were recruited from a list of operating refineries in the Lazio region, provided by the Ministry of Agriculture. The whole population was 530 refineries, located in the provinces of Viterbo, Rieti, Rome, Latina and Frosinone. The optimal sample size was identified by reaching the point of information saturation, which occurs when the researcher is not able to gather new evidence from the sources of information (Guest, Bunce, and Johnson, 2006). In particular, in order to reach this explanatory power, informants must belong to the same socio-economic group (Guest, Bunce, and Johnson, 2006) and be a minimum of 12 and a maximum of 15 individuals (Latham, 2013). In this instance, 13 refinery managers were identified as key decision-makers, since technicians in charge of the machinery were not employed by refineries at the time of the study (June-July 2018).

\subsection{Recruitment}

Recruitment of the respondents involved meeting with an official from the Lazio Region Ministry of Agriculture to obtain a list of the operating refineries in the region, along with their e-mail addresses and phone numbers. The next stage implied contacting between 12 to 15 refineries by e-mail to inform them of the research and ask for their participation. If the e-mail was not answered, a follow-up call was made after one week to enquiry on their availability/interest in the research. There were not any specific inclusion/exclusion criteria in place. Participants were only chosen based on their availability and willingness to be included in the study.

\subsection{Thematic Analysis}

Thematic analysis has been defined as an independent and reliable qualitative approach, which provides researchers with a tool adept at "identifying, analysing, and reporting patterns within data" (Braun and Clarke, 2006, p. 79). As this study makes use of semi-structured interviews to collect the data, performing a thematic analysis appeared to be the best option, in order to highlight common threads in a set of interviews (DeSantis \& Noel Ugarriza, 2000). According to Braun and Clarke (2006, p. 87), a thematic analysis follows these steps: familiarising with the data; systematically generating initial codes of interesting features; collating codes into potential themes and gathering data related to each theme; reviewing themes and creating thematic maps; defining the overall story the analysis tells; and finally producing a report relating back to the research question. The data were analysed and the themes have been identified via NVivo 11.

\section{RESULTS}

Common themes emerging from interview transcripts were structured into five thematic analysis areas according to the research's theoretical framework

1. Individual factors were the most recurring themes in the analysis and were represented by perceived usefulness, personal innovativeness and prior experience. 
2. Social influence exerted by peers, in terms of pressure groups, formed by other managers of nearby mills.

3. Organisational factors, with reference to training schemes and managerial support.

4. The impact of the olive oil value chain on quality.

5. Cost of the machinery affecting returns on investment.

\subsection{Sample Description}

Of the thirteen managers interviewed for this study, four were between 30 and 40 years old, another four belonged within the 41-50 age group, three were between 51 and 60 years old, and two were more than 60 years old. Moreover, ten managers were men and three were women, whilst five of them held a university degree in a scientific subject. However, in all cases managers had experienced the olive oil sector for a long time, and in $90 \%$ of the cases they had been in the managerial role for at least 10 years. In addition, ten refineries had belonged to the family for generations, while in three cases managers had started off their own business. Specifically, as it can be observed in Table 1 nine mills were small-sized, while four refineries were medium sized. Regarding the technology, ten mills adopted the continuous method of extraction, whereas three firms exclusively used the traditional pressing system. Also, seven refineries reported they had upgraded their machinery in the last six years. To name a few innovative devices: a touch-screen control panel to monitor and process different batches simultaneously, a malaxer working in absence of oxygen, ultrasounds to increase the extraction yield, and traditional grindstones incorporated into a modern continuous extraction plant. Moreover, the average number of workers employed in the refineries was eight, with larger mills registering up to fifteen employees. Ultimately, it was noted that there was not any specific correlation between age of the firm and innovativeness, as in some cases older refineries had upgraded their machinery more recently than younger ones.

\subsection{Individual Factors}

\subsubsection{Perceived Usefulness}

It was found that a recurring pattern linked the choice of the extraction machinery with enhanced performances and economic returns. Managers employing the modern extraction method claimed it maximises the yield, produces a higher quality olive oil and enhances organoleptic properties. In particular, this was seen as a source of competitive advantage.

One manager stated: "I have decided to use the modern extraction system, because it is faster and works with greater quantities, it maximises the yield and simply produces the best high-quality olive oil". However, half of those who had the modern extraction system still employed traditional hydraulic presses. This was due to the presence of a long-term clientele fond of the traditional method of extraction that guaranteed entries they did not want to lose. Specifically, a common answer was: "I understand that my refinery would never fulfil its potential if the migration to the continuous system is not total, but I find it is worth to maintain the presses, as still a good proportion of my 
Table 1. Economic data of refineries

\begin{tabular}{|c|c|c|c|c|c|}
\hline Refinery & Size (tonnes) & $\begin{array}{c}\text { Number of } \\
\text { workers }\end{array}$ & $\begin{array}{l}\text { Method of } \\
\text { extraction }\end{array}$ & $\begin{array}{l}\text { Last upgrade of } \\
\text { the machinery }\end{array}$ & $\begin{array}{l}\text { Age of the firm } \\
\text { (in years) }\end{array}$ \\
\hline 1 & Medium & 10 & Continuous & 2017 & $>100$ \\
\hline 2 & Medium & 15 & Continuous & 2010 & $40-50$ \\
\hline 3 & Small & 6 & $\begin{array}{l}\text { Continuous and } \\
\text { traditional }\end{array}$ & 2016 & $60-70$ \\
\hline 4 & Small & 4 & Continuous & 2012 & 10 \\
\hline 5 & Small & 4 & Continuous & 2013 & $30-40$ \\
\hline 6 & Medium & 9 & Traditional & 1998 & $30-40$ \\
\hline 7 & Small & 3 & Traditional & 2005 & $40-50$ \\
\hline 8 & Small & 8 & $\begin{array}{l}\text { Continuous and } \\
\text { traditional }\end{array}$ & 2012 & $50-60$ \\
\hline 9 & Small & 7 & Traditional & 2008 & 20 \\
\hline 10 & Small & 7 & Continuous & 2009 & 35 \\
\hline 11 & Small & 14 & $\begin{array}{l}\text { Continuous and } \\
\text { traditional }\end{array}$ & 2017 & $40-50$ \\
\hline 12 & Small & 4 & Continuous & 2010 & 10 \\
\hline 13 & Medium & 15 & $\begin{array}{l}\text { Continuous and } \\
\text { traditional }\end{array}$ & 2015 & 40 \\
\hline
\end{tabular}

clients ask for them". It was clear that managers wanted to fully migrate to modern extraction technologies, but this transition was difficult because of customers who were still attached to traditional methods. One manager said: "These clients are not interested in high organoleptic properties they can't directly experience, as they are convinced traditionally-extracted olive oil tastes better and it is healthier."

\subsubsection{Personal Innovativeness}

Managers who adopted innovative machinery acknowledged that their personal interest in advanced technology determined a positive attitude towards innovation. This recurring theme was also often linked to previous studies in scientific subjects, although that was not necessarily the case. For instance, one manager stated: "I have always been very passionate about touch screen technologies and electronics, and I always keep myself updated on the latest solutions. Even my phone is high-tech". In addition, these people reckoned that today innovation is crucial to succeed in every business and not only in the olive oil sector, as firms need to adapt to market changes. Specifically, it was said that: "Markets constantly evolve, and I feel I have to know what is happening. Today it is necessary to keep up with the world and try to anticipate the trend, if you want to stay competitive".

\subsubsection{Prior Experience}

Previous positive experience with innovative technologies made managers confident to purchase new similar versions, when the others became outdated, and it also helped 
them to keep an open-mind towards different solutions. In particular a common answer was: "When I bought this decanter, I thought that I could virtually use it forever by regularly servicing it. However, now that I have come to appreciate its potential, I will definitely consider buying a newer version or look into other innovative solutions in the future". Moreover, it was underscored that having a certain degree of familiarity with an innovative machinery speeds up the process of fitting a similar one into the organisation, because the needs and working capacity of the refinery are already known. Specifically, this is advantageous for technicians in charge of it, as they do not have to learn how to use it again. This way the transition is smoother, and it allows to quickly reiterate the innovation process within the organisation from time to time. One manager confirmed that by saying: "I do not have to worry too much about installing a new version of the same device, because my workers would almost already know how to use it. I think I can keep innovating in this way".

\subsection{Social Influence}

\subsubsection{Peers}

The influence local refineries had on a mill's strategy was manifested in various ways. In particular a common pattern related to managers who had faith in their local context, that tended to perceive other managers as colleagues and reliable sources of information. In fact, they considered sharing opinions on technologies and extraction techniques a mutual chance for improvement in the common challenge against nature. Thus, they were more likely to be persuaded to adopt an innovation. It was specifically reported that: "It is critical to always pay attention to what others have in place. Personally, I often discuss the machinery with managers of nearby mills to hear their opinions. It is a win-to-win situation". Furthermore, in some areas, managers were members of an online community of regional refineries, which organised big gatherings from time to time and was used as a platform for sharing opinions and news on technology. On the other hand, there were also cases in which a different trend emerged. Some managers stated that it is not possible to start a constructive dialogue with other refineries, because they are not cooperative and are jealous of their success. Indeed, it was actually stated that: "It is not possible to make a formative experience with your neighbours. That is because local managers are very jealous and do not want to cooperate". Moreover, other refineries were very focused on their own business and wanted to set the pace, without following anyone. Namely, a manager said: "I have clear in mind where I want to get, and I am focused on making it happen. Others can only follow me".

\subsection{Organisational Factors}

\subsubsection{Training}

It was widely recognised by managers that workers' knowledge and expertise in using an innovative process was considered an enabling factor for the adoption of new technologies. Even though, in a few instances, managers provided training schemes to their workers, overall, they did not believe it was worth investing in the formation 
of employers, that are only hired from three months per season. Actually, it was often said: "I cannot afford to slow down the production cycle to teach my workers how to use the machines. I only have three months a year and must maximise my extraction yield". Therefore, technicians in charge of the machinery were either already qualified to use the technologies or were employed in the logistics and undertook simple tasks. However, in some cases, unskilled workers shadowed experienced members of the staff and learned how to handle the technology. This was possible because the same labour force was employed every year, as these workers were already familiar with the technology and the premises. One manager said: "We employ the same people over the years, because they have gained additional skills here and have become essential to this business".

\subsubsection{Managerial Support}

It was common to find managers in the first line, dealing with all operational issues and often carrying out the extraction process together with technicians. This was possible because every manager had the skills and knowledge to run the extraction process. This circumstance happened because managers were aware disruptions and challenges always take place during the extraction cycle, so they wanted to help in the recovery, so as to reduce time losses. One manager pointed out that: "Supervising workers is fundamental, because if anything goes wrong I can intervene immediately and contact the external technical support to fix it. Otherwise, I would lose my clients." Moreover, this approach was seen as a way to protect the investment in technology and made managers feel more comfortable with technicians using the devices. Ultimately, providing managerial support induced a positive attitude towards innovation in employers, who felt supported and did not feel entirely responsible for the machinery, and in managers, who knew they could always protect their investment.

\subsection{The Impact of the Olive Oil Value Chain on Quality}

Every refinery had to conform with requirements dictated by the olive oil value chain and had to choose from a range of technologies which ensured such values every year. However, the majority of refineries were likely to choose a machinery that led to higher values, so as to gain a competitive advantage over the others by offering a higher-quality product. Namely, the goal was to increase phenolic compounds and lower acidity levels, in order to display quality certificates and attract more clients. In fact, one manager explained: "I really value quality and I know my client do, as well. My technologies must give them extras and show the olive oil extracted in my refinery stands out of the crowd". Generally, such views on quality were shared by innovative refineries, which preferred this characteristic over quantity. That said, in a few cases managers preferred a technology which only simplified the extraction process, without adding extras that were not perceived by the end-consumers. A statement which resumes this was: "My clients only want to have their olives transformed quickly and get the best yield. It is a waste of money to offer other things". 


\subsection{The Cost of the Extraction Machinery}

The majority of the interviewees referred to the cost of the extraction system in place, that had a significant financial impact to the current budget, and ultimately determined future purchase decisions regarding innovative technologies. Managers employing the modern extraction method chose to install it because, among yield-boosting and quality-enhancing benefits, it is cost-efficient in the long run. Specifically, one manager underlined: "The continuous extraction has considerably helped me reduce the number of workers I have to pay at the end of the season, because it only requires two/three technicians to manage the full cycle". However, buying this system is expensive and it takes some years to pay off the initial investment, so it inevitably postpones future upgrades of the machinery. On the contrary, the traditional extraction method is less expensive to purchase, but it was said to guarantee lower net margins, as it requires more workforce. This impaired the possibility of saving consistent sums to invest in modern devices. On the whole, costs were a challenge for almost every mill, and the situation is expected to worsen because next season (autumn and winter of 2018) several mills will not open. Indeed, every manager highlighted that: "This winter's frost damaged the shoots and next year we will have a very bad season. It will be probably not worth opening". Consequently, managers wanted to apply for financial plans, but many were discouraged by inventory and administrative costs and excessive bureaucracy of the procedure.

\section{DISCUSSION}

The analysis of the results showed that "individual factors" were the determinants, which were more linked to positive attitudes towards innovation adoption in the olive oil sector in the Lazio region. In particular:

Perceived usefulness determined a favourable attitude towards new technologies, as managers understood they could enhance performances to ultimately gain a competitive advantage in the market. Previous studies by Bhattacherjee \& Harris (2009) and Davis (1989) confirmed the enabling role of performance-enhancing innovations in stimulating a positive attitude towards adoption. In addition, Chian-Son and Yu-Hui (2009) highlighted that perceived usefulness strongly influences pre-decision and in-decision stages of technology adoption, which can help secure a strong market presence. Also, it can be inferred that by adopting innovative technologies managers deployed a long-term strategy to win young customers' loyalty and guarantee success in the long run, as traditional systems were preferred by middle-aged/old farmers. This was identified as a challenge to overcome, due to the inefficiency of such techniques. One plausible reason for this situation was the nature of the message passed on to clients. It was often found that managers promoted intangible characteristics, such as superior quality and excellent organoleptic properties, without sufficiently emphasising the practical benefits of advanced extraction method. Therefore, managers should underscore that innovative extraction systems not only enhance quality, but they yield more olive oil to the customer, as this was tested by several studies (Clodoveo, 2012; 
Di Giovacchino et al., 2002). This would certainly appeal to their clients, who are most of the times farmers who want to cover their annual supply of olive oil.

Personal innovativeness, on the other hand, induced a positive attitude towards innovation, but it did not have any effects on its ultimate adoption. This result is in contrast with Lee (2004) and Lee et al. (2006), who, instead, stated that innovativeness influences individuals to adopt innovation. Furthermore, significant direct effects on behavioural intention and innovation diffusion within an organisation have been empirically validated by other researchers (Yi et al., 2006; Bigné-Alcañiz et al., 2008). However, it should be noted that refineries almost exclusively rely on olives cultivated by third parties. Hence, it is not enough to be favourable to innovation, as new devices have to be welcomed by clients first, and only afterwards they can be justified by cost-efficiency, and profits.

Prior experience caused both a positive attitude towards innovation and intention to buy. Indeed, Talukder (2011) confirms that if individuals recall a positive experience with innovation, they would be very likely to use it again. This relationship was also underlined by other theoretical frameworks of innovation adoption (Aarons et al., 2011; Solomons and Spross, 2011). Specifically, a positive prior experience with innovation is critical for refineries that are not familiar with advanced technologies, as they can benefit from a hands-on experience, which would develop their views on innovation and influence their future decisions.

Furthermore, it was found that peers and training were not crucial determinants affecting innovation adoption. Namely, the influence of peers played a small part in determining behavioural intentions to adopt an innovation. In fact, although managers valued their peers' opinions, they were rarely persuaded by them. This result is in contrast with Yi et al. (2006), who highlighted that social influence is one of the most important antecedents of behavioural intention, and with Estrada and VargasEstrada (2013), who theorised that an individual's adoption decision is often guided by the pressure of those socio-culturally close to him/her. A plausible reason for this incongruence is that the Lazio region faced low producing years, and managers focused more on strategies to restore their business rather than paying attention to technologies employed by other mills. On the other hand, the reason why training schemes did not influence innovation adoption was the intense production regime happening in refineries during the three months of the extraction period. This is in contrast with Igbaria et al. (1997), Al-Gahtani and King (1999), and Lee et al. (2006), who highlighted that training schemes influence behavioural intention to adopt technological innovations, as they increase workers' knowledge and skills in using them. However, it is likely that managers believed they would lose their clients to more efficient mills, if they had to slow down the extraction process to train technicians. That is potentially why already qualified workers were preferred.

Lastly, one of the factors which negatively affected the rate of adoption of innovative technologies was the cost of machinery. Although in the Lazio region there are financial programmes supporting the agricultural sector, such as the PSR 2014-2020 (Plan for Rural Development), it came out that in olive oil sector few mills 
benefitted from them. This is in contrast with a study conducted by De Rosa and McElwee (2015) highlighting that a great number of agricultural firms applied for such measures in the Lazio region. The main obstacles in the olive oil sector seemed to be excessive bureaucracy and non-refundable application fees. Thus, in order to improve this situation, it would be key to reduce documents which do not require technical reports, representing unnecessary non-refundable costs, and allow applicants to send inquiries online, so as to avoid wasting time at regional offices. In addition, managers expressed their concerns about the next harvesting season (October to December 2018), which is expected to be very poor due to frost occurring in the winter of 2018 (January and February 2018). Specifically, harsh cold is not typical of the Italian weather, so farmers were not prepared to face it. This would slow down returns on investments and hinder innovation processes. Houliston et al. (2007) suggested to spray olive trees from January to June with an osmolyte, which protects cell proteins against denaturation and membranes against high concentration of inorganic ions during frosting, while increasing chilling tolerance in olives. This method should be taken into consideration by farmers, as it could lead to high-yielding seasons and save money for future investments in innovation. Moreover, as crop-failure for olive trees often depends on low rainfall (FAO, 2005), it is fundamental to know how to anticipate this circumstance in the future. Drip irrigation appears to be a feasible solution, as it allows water to flow into the rootzone of the tree, and it was studied to maximise yield and water efficiency in drought conditions, compared to mini-sprinkler and surface irrigation (Hijazi et al., 2014).

\section{LIMITATIONS OF THE RESEARCH AND CONCLUDING REMARKS}

The main drawback of qualitative research is that results are not generalisable to wider populations (Atieno, 2009). Furthermore, undertaking a field research project to collect data for the purpose of this study was expensive and time consuming. Therefore, activities had to be scheduled in advance and potential bias during data collection had to be minimised. That is because this type of research can lead a researcher to choose cases as a function of the desired outcome, and in the impartiality of the interviewer and participants while posing and answering questions (Hug, 2003). Moreover, technicians in charge of the machinery were not employed by refineries at the time of the study (June-July 2018), as the extraction process generally takes place between October and December. It was recognised they could have contributed to this research, through identifying new solutions in the market and pointing them out to managers. Thus, future work will try to include them in the research, along with focusing on other regions. In fact, it would be interesting to compare different cases and translate the results into national terms to have a more complete picture. 


\section{REFERENCES}

Aarons, G. A., Hurlburt, M., \& Horwitz, S. (2011). Advancing a conceptual model of evidence-based practice implementation in public service sectors. Administration and Policy in Mental Health, 38(1), 4-23. doi:10.1007/s10488-010-0327-7 PMID:21197565

Ajzen, I. (2005). Attitudes, Personality and Behaviour (2nd ed.). Milton Keynes: Open University Press.

Ajzen, I., \& Fishbein, M. (1980). Understanding Attitudes and Predicting Social Behaviour. Englewood Cliffs, NJ: Prentice-Hall.

Al-Gahtani, S., \& King, M. (1999). Attitudes, satisfaction and usage: Factors contributing to each in the acceptance of information technology. Behaviour \& Information Technology, 18(4), 277-297. doi:10.1080/014492999119020

Atieno, O.P. (2009). An analysis of the strenghts and limitations of qualitative and quantitative research paradigms. Problems of Education in the $21^{\text {st }}$ century, 13, 13-18.

Baregheh, A., Rowley, J., \& Sambrook, S. (2009). Towards a multidisciplinary definition of innovation. Management Decision, 47(8), 1323-1339. doi:10.1108/00251740910984578

Bhattacherjee, A., \& Harris, M. (2009). Individual adaptation of information technology. Journal of Computer Information Systems, 50(1), 37-45.

Bigné-Alcañiz, E., Ruiz-Mafé, C., Aldás-Manzano, J., \& Sanz-Blas, S. (2008). Influence of online shopping information dependency and innovativeness on internet shopping adoption. Online Information Review, 32(5), 648-667. doi:10.1108/14684520810914025

Brahma, S. S. (2009). Assessment of Construct Validity in Management Research: A Structured Guideline. Journal of Management Research, 9(2), 59-71.

Braun, V., \& Clarke, V. (2006). Using thematic analysis in psychology. Qualitative Research in Psychology, 3(2), 77-101. doi:10.1191/1478088706qp063oa

Bryman, A., \& Bell, E. (2015). Business Research Methods (3rd ed.). New York: Oxford university press.

Caiazza, R., Volpe, T., \& Stanton, J. L. (2016). Innovation in AgroFoods: A Comparative Analysis of Value Chains. Journal of International Food \& Agribusiness Marketing, 28(3), 240-253. doi:10.1080/08974438.2015.1068722

Carbone, A., Henke, R., \& Pozzolo, A. F. (2015). Italian agri-food exports in the international arena. Bio-Based and Applied Economics, 4(1), 55-75.

Chian-Son, Y., \& Yu-Hui, T. (2009). Understanding business-level innovation technology adoption. Technovation, 29(2), 92-109. doi:10.1016/j.technovation.2008.07.007

Chiavaro, E. (2014). A new decanter generation leads to innovation in olive oil processing. European Journal of Lipid Science and Technology, 116(12), 1615-1617. doi:10.1002/ejlt.201400289 
Clodoveo, M. L. (2012). Malaxation: Influence on virgin olive oil quality. Past, present and future - An overview. Trends in Food Science \& Technology, 25(1), 13-23. doi:10.1016/j.tifs.2011.11.004

Davis, F. (1989). Perceived usefulness, perceived ease of use, and user acceptance of information technology. Management Information Systems Quarterly, 13(3), 319-340. doi: $10.2307 / 249008$

Davis, F. D., \& Venkatesh, V. (2004). Toward preprototype user acceptance testing of new information systems: Implications for software project management. IEEE Transactions on Engineering Management, 51(1), 31-46. doi:10.1109/ TEM.2003.822468

De Rosa, M., \& McElwee, G. (2015). An empirical investigation of the role of rural development policies in stimulating rural entrepreneurship in the Lazio Region of Italy. Society and Business Review, 10(1), 4-22. doi:10.1108/SBR-08-2014-0041

De Santis, L., \& Noel Ugarriza, D. (2000). The concept of theme as used in qualitative nursing research. Western Journal of Nursing Research, 22(3), 351-372. doi:10.1177/019394590002200308 PMID:10804897

Di Giovacchino, L., Costantini, N., Ferrante, M. L., \& Serraiocco, A. (2002). Influence of malaxation time of olive paste on oil extraction yields and chemical and organoleptic characteristics of virgin olive oil obtained by a centrifugal decanter at water saving. Grasas y Aceites, 53(2), 179-186. doi:10.3989/gya.2002.v53.i2.302

Edwards, R., \& Holland, J. (2013). What is Qualitative Interviewing? Bloomsbury Academic.

Estrada, E., \& Vargas-Estrada, E. (2013). How peer pressure shapes consensus, leadership, and innovations in social groups. Scientific Reports, 3(2905), 1-6. PMID:24104951

European Commission. (2012). EU olive oil farms report based on FADN data. European Commission: Directorate general for agriculture and rural development.

FAO. (2005). Importance of olive-oil production in Italy. In Integrated soil and water management for orchard development.

Fishbein, M. (1967). Attitude and the prediction of behaviour. In M. Fishbein (Ed.), Readings in Attitude, Theory and Measurement. New York: John Wiley and Sons.

Fishbein, M., \& Ajzen, I. (1975). Belief, Attitude, Intention and Behaviour: An Introduction to Theory and Research. Reading, Mass.: Addison-Wesley.

Frambach, R., \& Schillewaert, N. (2002). Organizational innovation adoption: A multi-level framework of antecedents and opportunities for future research. Journal of Business Research, 55(2), 163-176. doi:10.1016/S0148-2963(00)00152-1

Guest, G., Bunce, A., \& Johnson, L. (2006). How many interviews are enough? An experiment with data saturation and variability. Field Methods, 18(1), 59-82. doi:10.1177/1525822X05279903 
Hijazi, A., Doghoze, M., Jouni, N., Nangia, V., Karrou, M., \& Oweis, T. (2014). Water requirement and water-use efficiency for olive trees under different irrigation systems. In 7th International Conf. on Water Resources in the Mediterranean Basin, Marrakech, Morocco, Oct 10-12.

Houliston, A., Vanhanen, L., \& Savage, G. (2007). Frost protection of olives using glycine betaine. Science and Technology, 108, 31-40.

Huang, L. J., Lu, M. T., \& Wong, B. K. (2003). The impact of power distance on Email acceptance: Evidence from the PRC. Journal of Computer Information Systems, 44(1), 93-101.

Hug, S. (2003). Selection Bias in Comparative Research: The Case of Incomplete Data sets. Political Analysis, 11(03), 255-274. doi:10.1093/pan/mpg014

Igbaria, M. (1993). User acceptance of microcomputer technology: An empirical test. Omega (Oxford), 21(1), 73-90. doi:10.1016/0305-0483(93)90040-R

International Olive Oil Council. (2015). Data from the international olive oil market (July). Retrieved from http://www.internationaloliveoil.org/

International Olive Oil Council. (2018). EU olive oil production. Retrieved from www. internationaloliveoil.org/

ISMEA. (2015). Piano di Settore Olivicolo-Oleario: Indagine sui costi di produzione e $i$ ricavi dei frantoi oleari. Retrieved from www.pianidisettore.it/flex/cm/pages/ ServeAttachment.php/.../BLOB\%3AID\%3D697

ISTAT. (2015). Italian olive oil production. Retrieved from http://agri.istat.it/jsp/ dawinci.jsp?q=plC270000040000133200\&an=2014\&ig=1\&ct=311\&id=15A $21 \mathrm{Al}$ $32 \mathrm{~A}$

Jackson, C. M., Chow, S., \& Leitch, R. A. (1997). Toward an understanding of the behavioural intention to use an information system. Decision Sciences, 28(2), 357-389. doi:10.1111/j.1540-5915.1997.tb01315.x

Kent, R. (2007). Marketing Research: Approaches, Methods and Applications in Europe. London: Thomson Learning.

Latham, J. R. (2013). A framework for leading the transformation to performance excellence part I: CEO perspectives on forces, facilitators, and strategic leadership systems. The Quality Management Journal, 20(2), 12-33. doi:10.1080/10686967.2 013.11918095

Lee, H., Lee, Y., \& Kwon, D. (2005). The intention to use computerized reservation systems: The moderating effects of organizational support and supplier incentive. Journal of Business Research, 58(11), 1552-1561. doi:10.1016/j.jbusres.2004.07.008

Lee, J. (2004). Discriminant analysis of technology adoption behavior: A case of Internet technologies in small business. Journal of Computer Information Systems, 44(4), 57-66. 
Lee, S., Kim, I., Rhee, S., \& Trimi, S. (2006). The role of exogenous factors in technology acceptance: The case of object-oriented technology. Information \& Management, 43(4), 469-480. doi:10.1016/j.im.2005.11.004

Lewis, W., Agarwal, R., \& Sambamurthy, V. (2003). Sources of influence on beliefs about information technology use: An empirical study of knowledge workers. Management Information Systems Quarterly, 27(4), 657-678. doi:10.2307/30036552

Marshall, M. N. (1996). The key informant technique. Family Practice, 13(1), 92-97. doi:10.1093/fampra/13.1.92 PMID:8671109

Monteleone, E., \& Langstaff, S. (2013). Olive Oil Sensory Science. John Wiley \& Sons, Incorporated.

Niavis, S., Tamvakis, N., Manos, B., \& Vlontzos, G. (2018). Assessing and Explaining the Efficiency of Extensive Olive Oil Farmers: The Case of Pelion Peninsula in Greece. Agriculture, 8(2), 25. doi:10.3390/agriculture8020025

Oh, S., Ang, J., \& Kim, B. (2003). Adoption of broadband internet in Korea: The role of experience in building attitudes. Journal of Information Technology, 18(4), 267-280. doi:10.1080/0268396032000150807

Orlandi, F., Aguilera, F., Galan, C., Msallem, M., \& Fornaciari, M. (2017). Olive yields forecasts and oil price trends in Mediterranean areas: A comprehensive analysis of the last two decades. Experimental Agriculture, 53(1), 71-83. doi:10.1017/ S0014479716000077

Palazzo, A. L., \& Aristone, O. (2017). Peri-urban matters. Changing olive growing patterns in central Italy. Sustainability, 9(4), 638. doi:10.3390/su9040638

Park, J. R., \& Dorward, P. T. (2007). Identifying and understanding factors influencing the uptake of new technologies on dairy farms in SW England using the theory of reasoned action. Agricultural Systems, 94(2), 281-293. doi:10.1016/j.agsy.2006.09.006

Plouffe, C. R., Hulland, J. S., \& Vandenbosch, M. (2001). Research Report: Richness versus parsimony in modeling technology adoption decisions-understanding merchant adoption of a smart cardbased payment system. Information Systems Research, 12(2), 208-222. doi:10.1287/isre.12.2.208.9697

Sabbatini, V., Gadanakis, Y., \& Areal, F. (2016). Variations on the effects of the 2003 CAP reform and regional differences in the Italian olive oil sector. International Journal of Food and Beverage Manufacturing and Business Models, 1(1), 48-60. doi:10.4018/IJFBMBM.2016010105

Salomone, R., Cappelletti, G. M., Malandrino, O., Mistretta, M., Neri, E., Nicoletti, G. M., \& Saija, G. et al. (2015). Life Cycle Assessment in the Agri-food Sector. Switzerland: Springer International Publishing.

Solomons, N. M., \& Spross, J. A. (2011). Evidence-based practice barriers and facilitators from a continuous quality improvement perspective: An integrative review. Journal of Nursing Management, 19(1), 109-120. doi:10.1111/j.13652834.2010.01144.x PMID:21223411 
Sullivan, T. J. (2001). Methods of Social Research. Orlando, FL: Hardcourt College Publishers.

Szajna, B. (1996). Empirical evaluation of the revised technology acceptance model. Management Science, 42(1), 85-92. doi:10.1287/mnsc.42.1.85

Talukder, M. (2011). Development of an Enhanced Model of Innovation Adoption by Individual Employees. Journal of Asia-Pacific Business, 12(4), 316-339. doi:10.10 80/10599231.2011.591691

USDA. (2017). Italy: Italian Olive Oil Overview. Retrieved from https://www.fas. usda.gov/data/italy-italian-olive-oil-overview-2017

Yi, M. Y., Fiedler, K. D., \& Park, J. S. (2006). Understanding the role of individual innovativeness in the acceptance of IT-based innovations: Comparative analyses of models and measures. Decision Sciences, 37(3), 393-426. doi:10.1111/j.15405414.2006.00132.x

Zecca, F., \& Rastorgueva, N. (2014). Supply Chain Management and Sustainability in Agri-Food System: Italian Evidence. Journal of Nutritional Ecology and Food Research, 2(1), 20-28. doi:10.1166/jnef.2014.1057

Domenico Zoccali is a graduate of the APD - International Development and Applied Economics department with a degree in the Food Economics and Marketing MSc programme.

Yiorgos Gadanakis research interests are Agricultural Economics, AgriBusiness management and Environmental Economics. In the past they have worked on: Evaluating sustainable agri-food systems and rural development in the Mediterranean Partner Countries (MPCs) Ex-post and ex-ante evaluation of rural development and regional plans strengthening innovation capacity and sustainability in agricultural sector Establishing common models of integrated sustainable monitoring, planning and management of high environmental value areas to control natural resources degradation" Research topic "Lefka Ori, the Greek case study" Measuring the impacts of distortions in the European Union cotton sector Their most recent research focuses on Sustainable Intensification of Agricultural Systems in the UK, measures of Total Factor Productivity and Technical Efficiency of farming systems. 